\title{
RESEARCH PAPER \\ SUCCESS INDICATORS FOR SELFBUILD HOUSES IN TWO GHANAIAN CITIES
}

\author{
D. K. Ahadzie ${ }^{1}$ and E. Badu ${ }^{2}$ \\ ${ }^{1}$ Centre for Settlements Studies, College of Architecture and Planning, KNUST, Kumasi \\ ${ }^{2}$ Department of Building Technology, College of Architecture and Planning, KNUST, Kumasi
}

\begin{abstract}
:
The recognition of success criteria for effective design and construction management purposes has been a topical issue in the housing construction industry for quite a while now. Yet, little is still known of the success indicators for SelfBuild houses, although these constitute the dominant mode of housing supply in many developing countries such as Ghana. To this effect, structured questionnaires were used to elicit from homeowners in two Ghanaian cities the importance they attach to a number of variables as determinants of success for Selfbuild houses, and the data analyzed using scale ranking and one-sample t-test. The analyses revealed that; adequate ventilation for thermal comfort (ranked no. 1), health and safety in the home (ranked no.2), quality of materials (ranked no. 3), quality of workmanship (ranked no. 4) and adequate daylight into rooms ranked (no. 5) are the main determinants of success in Selfbuild houses. The criteria cost and time received the lowest rankings of $10^{\text {th }}$ and $11^{\text {th }}$ respectively suggesting that while these traditional measures could be very important, in the long term they are not issues that Selfbuild homeowners might be particularly concerned about. The findings especially those relating to ventilation, health and safety in the home, quality of materials and adequate daylight are critical for dissemination to all construction professionals/practitioners regarding design decisions and choice of construction materials for Selfbuild houses in a tropical country like Ghana.
\end{abstract}

Keywords: Homeowners, Selfbuild houses and Success criteria

\section{INTRODUCTION}

The last decade or more has witnessed increasing research towards understanding the overall success model in housing projects in developing countries (Katilla, 1993; Ukoha and Beamish, 1997; Al-Momani, 2000; Arumala and Copeland, 2005; Ahadzie et al., 2008). However, many of these studies have focussed on mass house building projects ignoring Selfbuild houses which arguably account for the largest share of housing development in many developing countries such as Ghana. Indeed in Ghana, formal housing provision is largely of two forms: The first is large scale houses built by commercial speculative residential building companies such as those belonging to the Ghana Real Estate Developers Association (GREDA). The second is house building financed by individual owner-occupiers (herein referred to as "Selfbuild") often constructed by 
contracting small and/or labour only contractors.

Contextually, the term Selfbuild was originally used to describe a group of hippies in the UK who came together to build their own houses (Brinkley, 1997). The emphasis was on building cheap, simple and environmentally sound houses. However, later, the meaning changed and was used to describe community ventures where those who were financially challenged but wanted to own houses would contact "community Selfbuild agencies" for assistance in building. In the ensuing years, the meaning of the terminology again changed and is now used to describe people who want to be involved in "do-it yourself" (i.e. people being involved in the physical construction of their housing projects). This latest tradition of "do-ityourself" has largely remained so in the UK to date.

Although the original meaning of the term Selfbuild has not changed much in the Ghanaian context, there appears to be some variation obviously reflecting the culture of house building in Ghana. Just like the UK, people resort to Selfbuild in Ghana because they think it can help them build cheaper houses which they cannot otherwise obtain from the emerging speculative housing market. However, unlike the UK experience, people who resort to Selfbuild in Ghana do not necessarily involve themselves in do-it-yourself, but engage the services of designers and contractors (typically labour-only-contractors) to design and undertake the physical construction on their behalf. Thus, in Ghana, Selfbuild houses refer to the gradual piece- meal acquisition of housing inputs such as plots of lands, sand, various building materials in the housing construction process in tandem with the owners' resources flow and executed through the engagement of professional builders and artisans. Typically such Selfbuild houses could take between 5-10 years to complete (Ahadzie and Amoa-Mensah, 2010). This housing provision model does not promote the development of mass housing schemes. Nevertheless, it has since been the housing realization culture in Ghana and it currently accounts for about $90 \%$ of the housing stocks, and could be contributing about US\$ 300 million annually to the economy (World Bank, 2010). To this effect, empirical examination of the determinants of success from the perspective of homeowners would no doubt be an invaluable tool towards providing building features and practices that homeowners/ stakeholders in future Selfbuild housing programmes would ultimately be inured to.

Interestingly, the notion of project success remains an enigma with researchers still searching for agreement on concept and definitions (Pinto and Slevin, 1989; Baccarini, 1999; Cooke-Davies, 2002; Belout and Gauvreau, 2004). On this merit, the literature identifies two distinct perspectives; project management success and product success. Project management success focuses largely on the iron triangle of cost, time, and quality including the project management process while product success deals with the effects of the final product. That is, satisfaction of users during occupation (Wateridge, 1998; Torbica and Stroh, 2001). Significantly, the emerging consensus in contemporary times is that, the definition of success has shifted from using the so-called iron triangle as the foundation to treating them as measures amongst broader sets of criteria (Torbica and Stroh, 2001).

Within this context, some studies have revealed that success in house building could be influenced by users characteristics, dwelling unit characteristics, management and environmental and location factors (Awotona, 1991; Vrbka and Combs, 1991 cited in Ukoha and Beamish, 1997). The facilities and services available have also been identified as vital determinants (Morris and Winter 1978 cited in Ukoha and Beamish, 1997). On this note, Ukoha and Beamish (1997) proposed the following singleitem measures; structure types, building features, housing conditions, neighbourhood facilities and public housing management on a study 
they undertook relating to resident satisfaction on public housing in Nigeria. Al-Momani (2000) has also argued that, in evaluating the success of housing projects, homeowners attached considerable importance to the total housing environment focussing on characteristics such as capital investment, infrastructure requirement, land that the house occupies, quality of the house itself, neighbourhood and environment required. Torbica and Stroh (2001) also simplified the housing satisfaction model on three main constructs namely design, quality and service.

\section{METHODOLOGY}

Drawing on the established indicators in the literature especially in the context of developing countries, an exploratory study involving unstructured interviews was first undertaken. This interview involved talking to 10 homeowners on how they define a successful Selfbuild housing project and what experiences they can bring to bear on improving design and construction practices. The thematic issues emerging from the interview were compared with the constructs identified from the literature to establish their relevance or otherwise in the Ghanaian context. This preliminary interview confirmed the relevance of constructs used in previous studies. However, there were also emerging areas of relevance that led to the development of the conceptual framework in Fig. 1 .

Based on the concepts that emerged from the interview the variable "quality" was further operationalised as quality of material and quality of workmanship. The variable level of technical supervision was also principally linked to ensuring quality standards. The traditional measures of time, cost and quality are generally referred to as short-term criteria, as their relevance tends to wane after the project is put to use (Baccarini, 1997). Here, the level of supervision and workmanship were placed in the category of short-term criteria, while quality of materials was considered more of a long term criterion (see Fig 1). In this respect, the contention is that, the effect of poor quality of materials is more likely to almost always be a constant reminder to users or occupant of the affected property.

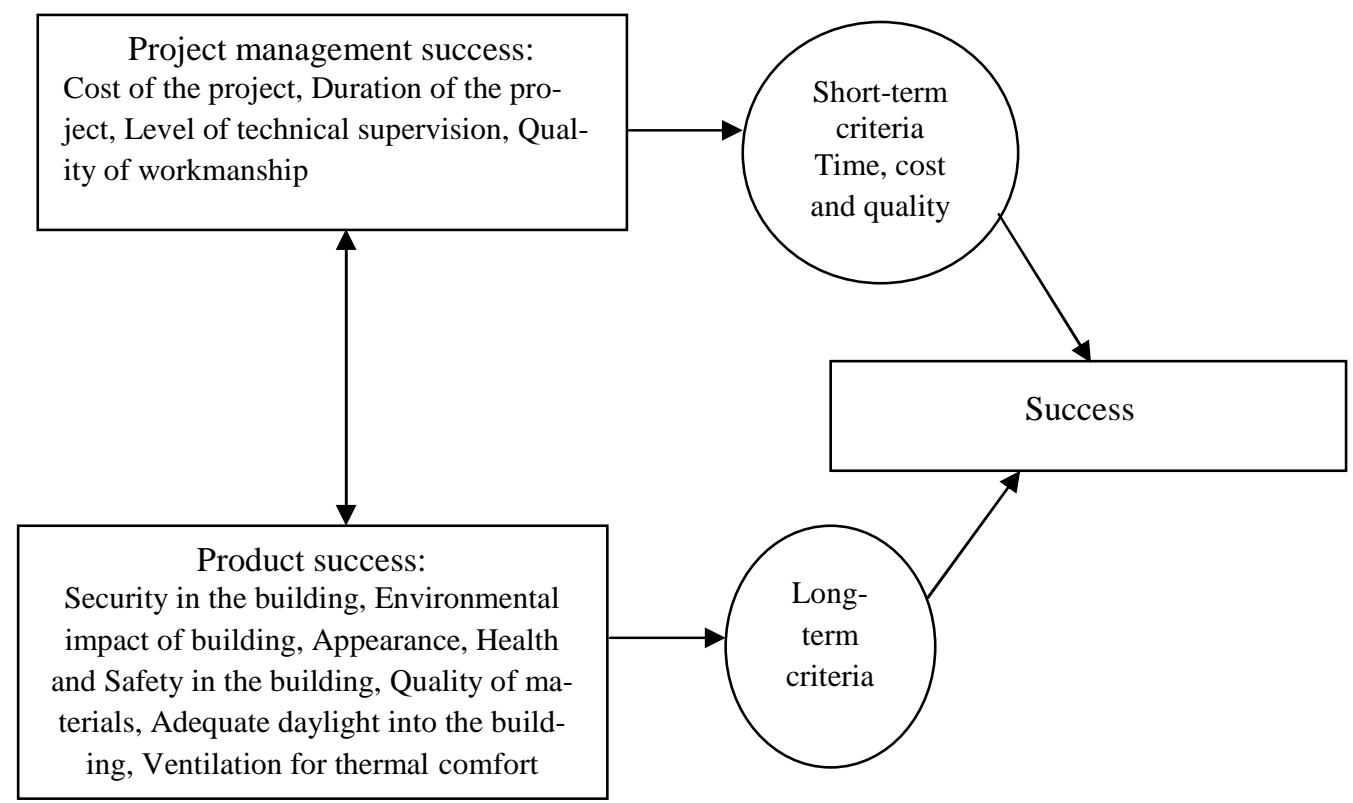

Fig. 1: Conceptual framework 
In Fig. 1, project management success is defined by the elements of the so called traditional measures including level of technical supervision. Alternatively, product success is defined by the so-called soft measures and also potential determinants such as adequate daylight into rooms and ventilation, thermal comfort and health and safety in the building. It is noted that, while health and safety have previously been identified in the success criteria model in the literature, in this instance, the meaning relates more to health and safety provided by the used structure as against health and safety during the construction process. It is the combination of these short-term and long term criteria (Fig. 1) that formed the basis for designing the survey instrument for this study in the Ghanaian context.

Given the lack of comprehensive records on registration and layout of house types in Ghana, it was difficult to draw from a structured list of homeowners from whom the relevant data would be elicited. In the same vain, it was difficult to establish a fair idea of the population involved. Subsequently, it was decided to draw the sample using purposive sampling technique. For this purpose, the questionnaires were distributed to people whom the researcher believed were true owners of the property and therefore were reasonably capable of providing the appropriate responses. Renters or tenants were not considered because it was felt that they might not feel comfortable providing answers on a property they do not have the right of ownership. The respondents targeted were mainly those living in single family- single storey houses constructed of sand and cement blocks (sandcrete). Drawing on recent survey research undertaken in Ghana (Danso, 2005; Ahadzie, 2007), 100 questionnaires were considered reasonable for this study, and subsequently 50 questionnaires each administered to homeowners in Accra and Kumasi, the two biggest cities in Ghana. The questionnaire comprised 11 variables as already identified in the conceptual framework (Fig 1). The respondents were asked to rank the variables on a five point
Likert scale of $5=$ very important, $4=$ important, $3=$ average, $2=$ not very important, $1=$ not important. The completed questionnaires received were 30 and 24 from Kumasi and Accra respectively representing a favourable response rate of approximately $50 \%$. Admittedly, the quality of results with Likert scales depends largely on the range of attributes given to the scale and clarity with which respondents interpret it. In this instance, the levels provided also reflected conventional practices in many studies of similar nature. Given that, the study targeted true owners of the houses, this should have generated sufficient confidence that the targeted respondents had the experience and knowledge to interpret the levels clearly.

\section{RESULTS AND DISCUSSIONS}

Examination of the completed questionnaires returned revealed that about $80 \%$ of the respondents have been living in their houses for more than 10 years, $10 \%$ for at least five years while the remaining $10 \%$ have only been living in their houses for three years. Mean ranking (using one-sample statistics) was first undertaken to establish the consensus reached by the respondents (Table 1). The small standard error suggests that most sample means were similar to the population mean and so the sample was likely to be a reflection of the population (Field, 2005). The results show that, adequate ventilation for thermal comfort emerged as the most important criterion (ranked number 1 with a mean of 4.85185) followed by health and safety in the building (ranked number 2 with a mean of 4.8333). Quality of workmanship was ranked $3^{\text {rd }}$ with a mean of 4.7963 , quality of materials was ranked $4^{\text {th }}$ with a mean of 4.7778 while adequate daylight into rooms was ranked $5^{\text {th }}$ with a mean of 4.7407 . The cost of building and time of completion traditionally considered as the foundation of performance measures emerged $10^{\text {th }}$ and $11^{\text {th }}$ respectively.

One sample t-test was also undertaken to determine whether the population considered a specific criterion to be important or otherwise. Table 2 provides a summary of the results. For 
Table 1: Mean ranking using one sample statistics

\begin{tabular}{|c|c|c|c|c|c|}
\hline & $\mathbf{N}$ & Mean & Std. Deviation & Rankings & $\begin{array}{l}\text { Std. Error of } \\
\text { mean }\end{array}$ \\
\hline Cost of building & 54 & 4.1481 & 1.12279 & 10 & .15279 \\
\hline Time of completion & 54 & 4.0000 & 1.18162 & 11 & .16080 \\
\hline $\begin{array}{l}\text { Environmental impact of } \\
\text { the building }\end{array}$ & 54 & 4.3889 & .87775 & 8 & .11945 \\
\hline Appearance of the building & 54 & 4.2407 & .77545 & 9 & .10553 \\
\hline Quality of materials & 54 & 4.7778 & 63444 & 4 & .08634 \\
\hline Quality Workmanship & 54 & 4.7963 & .40653 & 3 & .05532 \\
\hline Level of Technical supervision & 54 & 4.4444 & 60397 & 7 & .08219 \\
\hline Adequate Daylight into rooms & 54 & 4.7407 & 64968 & 5 & .08841 \\
\hline $\begin{array}{l}\text { Adequate ventilation for } \\
\text { thermal comfort }\end{array}$ & 54 & 4.8519 & .40782 & 1 & .05550 \\
\hline Health and safety in the building & 54 & 4.8333 & .42337 & 2 & .05761 \\
\hline Security consideration in building & 54 & 4.7222 & .52903 & 6 & .07199 \\
\hline
\end{tabular}

each criterion, the null hypothesis was that it was unimportant (Ho: $\mathrm{U}=\mathrm{Uo}$ ) and the alternate hypothesis was that it was important (Ha:U > Uo) where Uo is the population mean (Uo was fixed at the conventional test value of 3.5 at $95 \%$ confidence level. Thus, based on the five-point Likert scale, a success criterion was deemed to be critical or important if it had a mean value of 3.5 or more. These findings as demonstrated by the p-values (one-tailed, $\mathrm{U}>$ Uo) indicate that the man values for all the variables were statistically significant.

Project success is an illusory concept, yet until stakeholders agree on determinants, attempts to accurately monitor and anticipate project outcomes will be severely restricted (Pinto and Slevin, 1987). From the perspective of homeowners, the findings of this study do present some interesting concerns that are potentially linked to the design and management of the construction of Selfbuild houses in Ghana. Indeed, in a tropical country such as Ghana where daytime temperature can peak to as high as 33 degrees Celsius for most part of the day, ade- quate ventilation is no doubt required to help provide reasonable thermal comfort in the home. The topmost ranking of ventilation as the number one important criterion in this study is thus very noteworthy because of its strong correlation to enjoying thermal comfort and health and safety in the homes. As noted by Jackson (2003), and also re-echoed quite recently by Koranteng and Abaitey (2010); indoor quality, humidity, indoor temperatures are amongst the many key factors influencing residential health generally. The Ghana Institution of Architects (GIA) has also only recently brought to focus concerns of inadequate ventilation in contemporary Ghanaian buildings, advising architects to look at this issue seriously towards engendering energy conservation (Daily Graphic, 12 October 2010, pg 32). An observation by Tung et al. (2005) that the provision of adequate ventilation is an effective means to reduce radon concentration indoors is also relevant in this respect. Thus, designers have an obligation to ensure adequate ventilation in the homes as this does not only border on providing thermal comfort but also on the health and safety of 


\section{Ahadzie and Badu}

occupants. Within this context, Koranteng and Abaitey (2009) also suggests that, other design parameters such as configuration of spaces, functions, shading and passive design methods must be promoted for an environmentally sound tropical architecture for residential buildings in Ghana (see also Koranteng and Abaitey, 2010).

Traditionally many of the studies addressing project success have looked at health and safety from the perspective of project management practice and contractor development especially at the site level. Health and safety in the home itself has not been subjected to rigorous studies even though the housing environment has long been acknowledged as one of the main settings of human health (Jackson, 2003). In this study, health and safety in the building was ranked $2^{\text {nd }}$ just after ventilation. The reality is that many health problems could directly or indirectly be related to buildings and this could arise from the construction materials that were used, the equipment installed and the size or design of the dwellings. Bonnefoy (2007) also notes that, epidemiological findings suggest strong associations between housing conditions and health effects. Concomitantly, Bonnefoy (2007) further observes that, to date there is no commonly agreed definition of 'healthy housing', and there are still major gaps in the knowledge on how housing conditions may affect health. Within this context, there is also presently no known empirically robust study establishing the relationship between health and housing standards in Ghana. Hopefully, this finding from the per-

Table 2. One-Sample T-Test

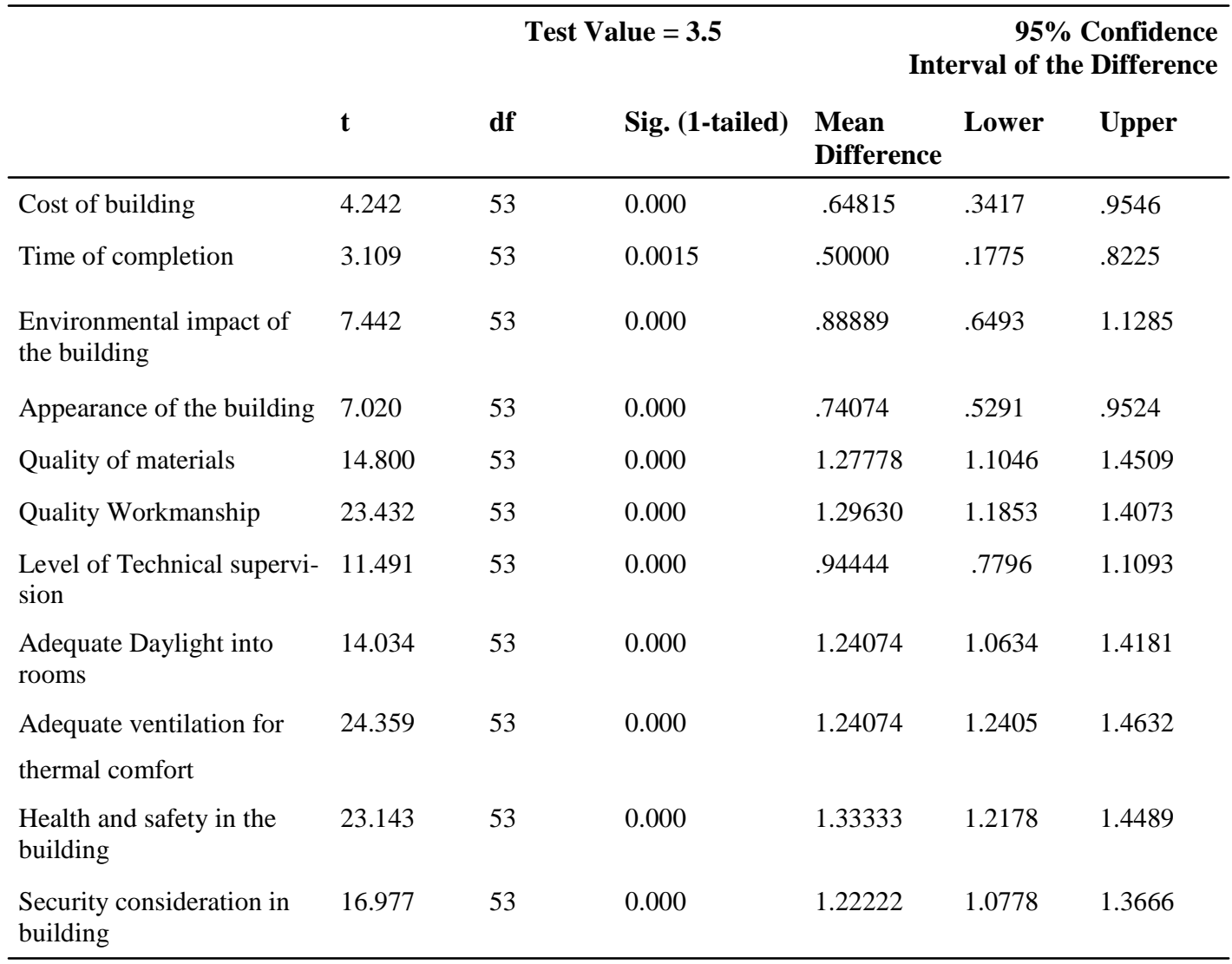


spective of homeowners should help refocus Ghanaian researchers' interest towards initiating studies to understand the situation better so that a comprehensive approach could be built towards providing healthy housing.

The significance of quality improvement in housing construction is an issue that has been addressed in a plethora of literature (Toole, 1998; Kazaz and Birgonul, 2005, Liu, 2003). Indeed conclusions drawn on most studies around the world including Ghana recognised the importance that clients and many stakeholders attached to the issues of quality (AlMomani, 2001; Kazaz, 2005 and Birgonul, 2005; Ahadzie et al, 2008). In this study, homeowners ranked quality of workmanship as the $3^{\text {rd }}$ most important criteria behind ventilation and health and safety in the building, while quality of materials followed closely at $4^{\text {th }}$ position. This suggests that the homeowners who responded were not oblivious of the correlation between workmanship and quality of the end product. Contextually, the quality and condition of materials also play a decisive role in the health status of residents (Bonnefoy, 2007). The reality is that, no two identical houses were the same in quality because of variations in construction process, skills and attitudes of tradesmen and whether specified materials were correctly delivered and installed (Toole, 2001). Furthermore, in Ghana, most Selfbuild construction are executed and managed by labour-only contractors, whose training and background are not clearly and/or professionally established, because of the lack of a wellestablished and monitored apprenticeship programme. Indeed, the World Bank (2010) reports that although the artisans could generally be described as hardworking, about $90 \%$ of them do acquire their training through the informal apprenticeship of learning from master gangmen who are often also limited in capacity.

This limitation often affects the capacity of the artisans towards adhering to good code of practice and specifications to ensure high quality standards (World Bank, 2010). Thus, if the issue of quality is to be addressed holistically in Ghana, the training regime of artisans should be examined with a view to introducing appropriately designed skills and certifications programmes towards improving their vocational ethics.

Daylight is widely accepted to have a positive psychological effect on human beings. Daylight is also no doubt a very important issue for a tropical country like Ghana, especially given the huge energy challenges confronting the country. From Table 1, adequate daylight into rooms was ranked $5^{\text {th }}$. This finding provide impetus for recent interest in studies towards improving energy performance in residential buildings in Ghana (Abanyie, 2008; Koranteng and Abaitey, 2009; 2010a and b). Truly, in Ghana, energy supply has not been able to meet housing demand and load shedding exercises have often been used as a way of meeting demand (e.g. the 2006 load shedding exercises which run until 2007). Anecdotes also exist as to why in a tropical country like Ghana, some residents often have to put on lights even during the day time in their rooms. It is therefore refreshing that at least in the study area, research into improving energy performance is gradually gaining grounds (Koraenteng and Abaitey, 2009). This study should reinforce interest in promoting research into how efficient utilization of daylight can be integrated into the current study programmes.

In this study, security consideration in the building was ranked $6^{\text {th }}$. This suggests that security perhaps is not much of a priority as far as the targeted respondents are concerned. Indeed, Everett (2007), has argued that the priority given security situations is normally dictated by the precise function and location of a specific building. Given that different locations might come with different security concerns, it is possible that the location of the buildings might have influenced how the respondents felt. Thus, the issue of security would need further studies and clarification before one can attempt to draw any plausible firm conclusion. 


\section{Ahadzie and Badu}

The importance of appropriate supervision of site operatives cannot also be discounted. This is because the level of technical supervision provided affects both the quality of workmanship as well as the quality of the end product. However, in this context the homeowners ranked level of supervision as the $7^{\text {th }}$ most important criterion.

Environmental impact of construction activities (although ranked $8^{\text {th }}$ in this study) is also no longer a concept but has now become a worldwide challenge facing the construction industry. Morrel et al. (2000) also cautions that as the demand for housing increases, widespread use of high energy materials such as aluminium, cement, concrete and steel must comply with directives aimed at protecting the environment in areas such as the emission of carbon dioxide, reduction of quarries, obligation to rehabilitate quarries and the protection of materials from river beds. The irony is that, while the need to preserve the environment is increasingly becoming important, developing countries in particular are not well positioned to face these challenges. Furthermore, education and training on environmental science, technology and management is still evolving and leaves much to be desired (Ayarkwa et al., 2010).

Al-Momani (2000) identified appearance as one of the potential key factors that must receive consideration in house design. In this study, appearance of the building with regards to design and aesthetics was ranked $9^{\text {th }}$. This could be described as surprising because on face value one would expect the physical attraction of the building to be probably the most easily identifiable parameter one can identify with. A plausible conclusion is that, while appearance indeed might matter in house-design, homeowners are perhaps often more particular about how the appearance will also translate into achieving a good functional building and not mere aesthetics.

Many researchers have in recent times argued that the traditional measures of success, par- ticularly cost and time, albeit important often have short-term effect in the determinants of contemporary success dimensions (Bacarrini, 1999: Torbica and Stroh, 2001). The Ghanaian context appears to add impetus to this consensus as cost of building and time of completion were ranked $10^{\text {th }}$ and $11^{\text {th }}$ respectively. As noted by Brinkley (1997), Selfbuilders are not often in any hurry to build and thus completion time might mean very little to the individual house owners except in rare cases where the individual faces ejection from present residence or wants to move into his own property within a specific time period. Similarly, because many Selfbuild homeowners build through the incremental building process which can take several years, it is possible that by the time the project is completed they are not very much in touch with how much money has really gone into the project let alone to focus on establishing a firm idea of completion cost.

\section{IMPLICATIONS OF THE FINDINGS}

According to Ukoha and Beamish (1997), simply providing houses do not measure the success of housing programmes. The suitability of the living environment to the needs of residents is essential for judging successful houses. It is also clear that resident satisfaction is not absolute, and housing conditions are not static (Ukoha and Beamish, 1997). That is the more reason why criteria for project success must be continuously established and continuously updated from all possible perspectives. This study has brought to the fore some useful success dimensions in Selfbuild houses in Ghana which cannot be ignored if the housing sector is to work towards satisfying potential homeowners in the future. The most striking findings are those relating to ventilation, health and safety and daylight, ranked amongst the top five determinants of success in Selfbuild houses in the two major Ghanaian cities. It is also striking to observe that the first five criteria that emerged namely; ventilation, health and safety in the home, quality of materials, quality of workmanship and daylight all appears related to ensuring a healthy home. This suggests some sort of 
consistency in the rankings which should provide confidence in the data collected. Given that Selfbuild houses in Ghana are significantly dominant in the two cities used for the study, it would not be far-fetched for one to suggest that these findings are a reflection of how homeowners feel across the country.

Form these findings, three main implications arise: 1) while the study was addressed from the perspective of success dimensions, an important platform has been created to justify a more comprehensive study towards understanding the nature and also satisfaction levels of homeowners in Selfbuild houses in Ghana. For example, the emerging factors such as ventilation, health and safety in the home, and daylight are now very much relevant in contemporary Ghana ; 2) designers will need to reflect and re-orient their design practices to make these factors a priority in their designs; 3) admittedly, the range of variables considered excluded some other important building characteristics such as noise control, quality of services (e.g. electrical, plumbing) and design qualities such as functionality of layout and maintenance facility. These variables could also be considered in a future study to further help clarify the appropriate success model for Selfbuild houses. As noted by Bonneroy (2007), a successful house must be a comprehensive concept taking into consideration a variety of factors contributing to the quality of housing and housing environment.

\section{CONCLUSION}

This study has attempted to address what constitute the determinants of success in Selfbuild houses in Ghana from the perspective of homeowners. The study is significant inasmuch as it provides a basis for understanding the overall success model in housing projects in Ghana. The findings suggest that there are important contemporary issues that need to be further examined if successful Selfbuild houses are to be delivered. These are issues relating to ventilation, health and safety in the home, quality of materials, quality of workmanship and daylight.
The findings have implications for designers and construction practitioners towards meeting the aspirations of homeowners and/or potential homeowners in future Selfbuild houses in Ghana. It is also advocated that with limited knowledge on the effect of these variables on homeowners in Ghana, further studies are required to help provide a better understanding of the impact of these emerging variables in the home environment.

\section{AKNOWLEDGEMENT}

The authors wish to acknowledge the services of $\mathrm{Mr}$ Anthony Gbewonyo, a former student of the Department of Building Technology, KNUST who collected the data.

\section{REFERNCES}

Ahadzie, D. K. and Amoa-Mensah, K. (2010). Management Practices in the Ghanaian House Building Industry, Journal of Science and Technology, 30 (2): 62- 74.

Ahadzie, D. K., Proverbs, D. G. and Olomolaiye, P. (2008). Critical success criteria for mass house building projects in developing countries, International Journal of Project Management, 26: 675 - 687.

Ahadzie, D. K. (2007). A Model for Predicting the Performance of Project Managers in Mass House Building Projects in Ghana, $\mathrm{PhD}$ Thesis (Unpublished), University of Wolverhampton, UK.

Abanyie, S. A. (2006). Implications of Climate Change on Human Comfort in Buildings: Evidence from Okontompo Community of Sekondi-Takoradi, Ghana, Journal of Science and Technology, 26 (1): 102-115.

AL-Momani, A. H. (2000). Structuring information on residential buildings: a model preference, Engineering Construction and Architectural Management, 7 (2): 179190.

Arumala, J. O. and Copeland, L. L. (2005). 


\section{Ahadzie and Badu}

Affordable Housing in Developing Countries: The EMES experience in Ghana. ASC proceedings of the $41^{\text {st }}$ Annual Conference, University of Cincinnati, Ohio, April 6- 9, 2005.

Awotona, A. (1991). Nigerian government participation in housing: $1970-1980$, Nigeria, Social Indicators Research, 25: 63 98.

Ayarkwa, J., Danso, A. and Amoah, P. (2010). Barriers to Implementation of Environmental Management Systems (EMS) in the Construction Industry in Ghana, $1^{\text {st }}$ International Postgraduate Research Conference on the Built Environment, July, 2010, KNUST, Kumasi, 43-57.

Baccarini, D. (1999). The Logical Framework Method for Defining Project Success, Project Management Journal, 30 (4): 25- 32.

Belout, G. and Gauvreau, C. (2004). Factors influencing project success: the impact of human resource management, International Journal of Project Management, 22: $1-11$.

Bonnefoy, X. (2007). Inadequate Housing and Health: an Overview, International Journal of Environmental Pollution, 30 (3/4): 411-429.

Brinkley, M. (1997). An Insider's Guide through the Housebuilding Jungle, HouseBuilders's Bible, Rodelia Ltd, London

Cooke-Davies, T. J. (2002). The real success factors on projects, International Journal of Project Management, 20: 185-190.

Danso, A. (2005). Strategic planning practice of construction firms in Ghana, Construction Management and Economics, 23: 148 $-163$.

Everett, E. (2007). Mitchells Building Series, $4^{\text {th }}$ Edition, B.T. Batsford Limited, UK.

Field, A. (2000). Discovering Statistics using SPSS for Windows, Sage Publications, London

Formoso, C. T., Tzartzorpoulous, P. and Liedtke, R. (2002). A model for managing the product development process in house building, ECAM, 9 (5/6): $419-432$.

Gbewonyo, A. (2010). Criteria for Assessing the Success of SelfBuild Residential Buildings, BSc Dissertation, Department of Building Technology, KNUST

Jackson, R. J. (2003). The Impact of the Built Environment on Health: an emerging Field, American Journal of Public Health, 39 (3): $1382-1384$.

Kattila, S. (1993). Satisfaction with public housing in Papua New Guinea: the case of West Taraka Housing scheme, Environment and Behaviour, 25: 514-545.

Kazaz, A. and Birgonul, J. (2005). The evidence of poor quality in high rise and medium rise housing units: a case study of mass housing projects in Turkey, Building and Environment, 40: 1548 - 1556.

Koranteng, C. and Abaitey, E. G. (2010). The Effects of Form and Orientation on Energy Performance on Residential Buildings in Ghana, Journal of Science and Technology, 30 (1): $71-81$.

Koranteng C. and Abaitey, E.G. (2009a). Simulation Based Analysis of the Effects of Orientation on Energy Performance of Residential Buildings in Ghana, Journal of Science and Technology, 29 (3): $86-101$.

Koranteng, C. and Abaitey, E.G. (2009b). The effect of Forms and Orientation on Energy Performance of Residential Buildings, Journal of Science and Technology, 30 (1): 
$71-81$

Liu, A. (2003). The quest for quality in public housing projects: a behaviour -to-outcome paradigm, Construction Management and Economics, 21: 147 - 158.

Morel, J. C., Mesbach A., Oggero, P. and Walker, P. (2006) Building houses with local materials: means to drastically reduce the environmental impact of construction, Building and Environment, 36: 119 -126.

Owusu, S. E. and Tipple G. A. (1995). Transformation of Government Built Low Cost Housing as Generators of Shelter and Employment, ODA research number series.

Ozsoy, A., Atlas, N. E., OK, V. and Pulat, G. (1996). Quality Assessment Model for Housing: A case Study on outdoor Spaces in Istanbul, Habitat International, 20 (2): $163-173$.

Pinto J. K. and Slevin, D. P. (1988). Critical Success factors in effective project implementation, Project Management Journal, 19 (1): $67-71$.

Torbica, M. Z. and Stroh, R. C. (2001). Customer Satisfaction in Home Building, ACSE Journal of Construction Engineering and Management, 127 (1) : $82-86$.
Toole, M. (1998). Uncertainty and homebuilders adoption on innovations, ASCE, Journal of Construction Engineering and Management, 124 (1): $323-332$

Tung, T. C. W., Chan, D. W. T., and Burnett, J. (2005). An Empirical Radon Emanation for Residential Premises, Building and Environment, 40 (1): 1566 - 1571.

Tweneboa, A. (2008). Solving the housing deficit problem in Ghana, Ghana Review International, Ghana 2008 Edition, 125: 45.

Ukoha, O. M. and Beamish, J. O. (1997). Assessments of Residents Satisfaction with Public Housing in Abuja, Nigeria, Habtitat International, 21(4): 445-460.

Vrbka, S. J. and Combs, E. R. (1991.) Predictors of Neighbourhood and Community Satisfaction, Environment and Behaviour, 10 (4): $459-488$.

Wateridge, J. (1988) How can IS/IT projects be measured for success, International Journal of Project Management, 16 (1): 59 - 63.

World Bank (2010). Ghana Skills and Techno logy Development Project (GSDTP) (Unpublished Report), Accra, Ghana. 